\title{
In-situ observation on the transformation of calcium phosphate cement into hydroxyapatite
}

\author{
Hsiu-Ching Hsu ${ }^{a}$, Wei-Hsing Tuan ${ }^{a}, *$, Hsin-Yi Lee ${ }^{b}$ \\ a Department of Materials Science and Engineering, National Taiwan University, Taipei 106, Taiwan \\ ${ }^{\mathrm{b}}$ National Synchrotron Radiation Research Center, Hsinchu 300, Taiwan
}

\section{A R T I C L E I N F O}

\section{Article history:}

Received 20 March 2008

Received in revised form 10 August 2008

Accepted 15 August 2008

Available online $\mathrm{xxxx}$

\section{Keywords:}

Calcium phosphate cement

Hydroxyapatite

XRD

Microstructure

\begin{abstract}
A B S T R A C T
In the present study, the in-situ transformation of calcium phosphate cement into hydroxyapatite (HAp) within the first hour is monitored with a synchrotron X-ray beam. A disodium hydrogen phosphate solution is used as cement liquid to activate the reaction between dicalcium phosphate anhydrous (DCPA) and calcium hydroxide $\left(\mathrm{Ca}(\mathrm{OH})_{2}\right)$. The XRD analysis indicates that the amounts of DCPA and $\mathrm{Ca}(\mathrm{OH})_{2}$ first decrease within the first min of the reaction. Then, the intensity of DCPA's XRD peaks starts to increase instead in the period of 5 to $20 \mathrm{~min}$. After $20 \mathrm{~min}$, the DCPA particles are consumed slowly to form fine HAp particles. Large pores are evident upon the completion of reaction.
\end{abstract}

(c) 2008 Elsevier B.V. All rights reserved.

\section{Introduction}

Calcium phosphate cement $(\mathrm{CPC})$ has received wide interest for its potential use as a bone cement material [1-4]. For example, it has been used as the fixation of artificial joints to bone stock [5]. CPC is usually prepared by mixing two or three calcium containing ceramic powders together. A cement liquid is then added to activate the reaction between the starting powders. Phase transformations occurred during the cementation process underline the setting behavior and stability of CPC. Previous studies demonstrated that the investigation into the reactions during setting could lead to an improvement in the properties of CPC [6-8].

Several formulations of calcium phosphate cements have been used as the starting materials for bone cement [1,9-11]. Among these formulations, dicalcium phosphate anhydrous $\left(\mathrm{CaHPO}_{4}\right.$, Monetite, DCPA) and calcium hydroxide $\left(\mathrm{Ca}(\mathrm{OH})_{2}\right)$ are frequently used. Typically, a disodium hydrogen phosphate $\left(\mathrm{Na}_{2} \mathrm{HPO}_{4}\right)$ solution is added to activate the reaction between DCPA and $\mathrm{Ca}(\mathrm{OH})_{2}$ [12-14], and hydroxyapatite $\left(\mathrm{Ca}_{10}\left(\mathrm{PO}_{4}\right)_{6}(\mathrm{OH})_{2}\right.$, $\left.\mathrm{HAp}\right)$ is the major product of the reaction. In order to avoid any contamination, the clinically acceptable period of time for the setting of bone cement is usually very short. For examples, the setting time for several calcium phosphates is in the range of $5 \mathrm{~min}$ to 30 min $[1,11,15-18]$. However, the information on the phase transformations from calcium phosphates to bone cement in the first $60 \mathrm{~min}$ is very limited. A very high energy X-ray source is needed to monitor the phase transformations within a very short time. In the present study, an X-ray source generated by a synchrotron is used. The

\footnotetext{
* Corresponding author. Tel.: +886 2 23659800; fax: +886 223634562 E-mail address: tuan@ntu.edu.tw (W.-H. Tuan).
}

microstructure evolutions of the bone cement after the addition of cement liquid are also investigated.

\section{Materials and methods}

\subsection{Preparation of specimens}

Reagent grade dicalcium phosphate anhydrous (DCPA; $\mathrm{CaHPO}_{4}$, $>99 \%$, Acros Organics Co., USA) and calcium hydroxide $\left(\mathrm{Ca}(\mathrm{OH})_{2},>98 \%\right.$, Acros Organics Co., USA) powders were used as the starting materials for $\mathrm{CPC}$. In order to produce a powder mixture with a $\mathrm{Ca} / \mathrm{P}$ ratio of $1.67,60.0 \mathrm{~g}$ of DCPA and $21.5 \mathrm{~g}$ of $\mathrm{Ca}(\mathrm{OH})_{2}$ were used for each batch. The powders were milled in an attritor (Model 01-HD, Union Process Co., Ohio, USA) with ethyl alcohol at a rotation speed of $500 \mathrm{rpm}$ for $6 \mathrm{~h}$. After milling, the slurry was dried using a rotary evaporator and then sieved through a \#150 plastic sieve. The size distribution of the powder was determined by a laser particle size analyzer (Mastersizer-2000, Malvern Co., UK). The solution of $1.0 \mathrm{M}$ disodium hydrogen phosphate $\left(\mathrm{Na}_{2} \mathrm{HPO}_{4}, 99.9 \%\right.$, ACROS Organics Co., USA) was used as the cement liquid. The mixture of DCPA and $\mathrm{Ca}(\mathrm{OH})_{2}$ powders was first formed into cylindrical discs by uniaxial pressing at $10 \mathrm{MPa}$. The discs had a diameter of $10 \mathrm{~mm}$, a thickness of $3 \mathrm{~mm}$, and a weight of $0.50 \mathrm{~g}$.

\subsection{Phase and microstructure characterization}

For the phase analysis, the specimen disc was loaded into a synchrotron X-ray stage. The X-ray diffraction (XRD) analysis started immediately upon the injection of $\sim 0.25 \mathrm{~mL}$ cement liquid into the center of the specimen disc. Since the rates of phase transformations during setting were very quick, an X-ray source with high intensity 
was used in the present study. The X-ray beam was generated from the Synchrotron in the National Synchrotron Radiation Research Center (NSRRC), Hsinchu, Taiwan. Incident X-ray was focused vertically with a mirror and made monochromatic at $8 \mathrm{KeV}$ with a $\mathrm{Si}$ (111) doublecrystal monochromator. The sagittal bend of the second crystal focused the X-ray in the horizontal direction. With two pairs of slits between the sample and the detector, the typical scattering vector resolution in the vertical scattering plane was set to $\sim 5 \times 10^{-3} \mathrm{~nm}^{-1}$ in these experiments. The X-ray scanning rate was $0.05^{\circ} 2 \theta / \mathrm{s}$. A twodegree range, for example $25^{\circ}$ to $27^{\circ}$ of $2 \theta$, was first scanned repeatedly to obtain the in-situ observation results. Then, the next two degrees were scanned by using another new specimen. By repeating the same procedures, the diffraction angles from $25^{\circ}$ to $35^{\circ}$ of $2 \theta$ were measured. A slight increase of temperature might be resulted from the $\mathrm{X}$-ray beam. The reactions occurred during setting in the specimens might not be the same as those taken place inside a human body. The data obtained in the present study therefore could only be treated as the results under a "simulated" condition.

The phase transformations were also analyzed using Fourier transform infrared spectroscopy (FT-IR, FT/IR-410, JASCO Co., Ltd., Japan). The analysis was conducted in the range of $4000-400 \mathrm{~cm}^{-1}$ with a resolution of $8 \mathrm{~cm}^{-1}$. The microstructure was observed with a fieldemission scanning electron microscope (FE-SEM, model 1530, Leo Electron Microscopy Ltd., UK) under $5 \mathrm{kV}$. The composition analyses on the powder compacts were carried out using energy dispersive X-ray spectroscopy (EDX, LEO Instrument, Cambridge, UK) or an electron

(a)

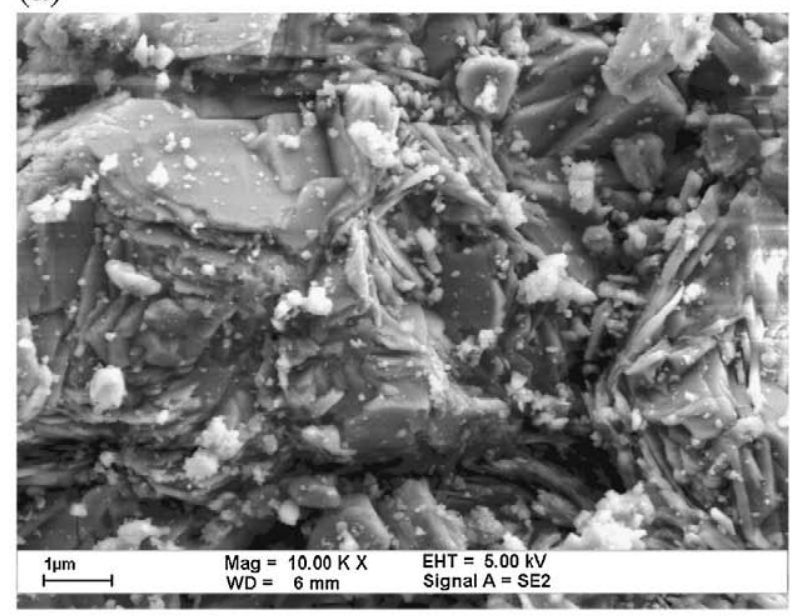

(b)

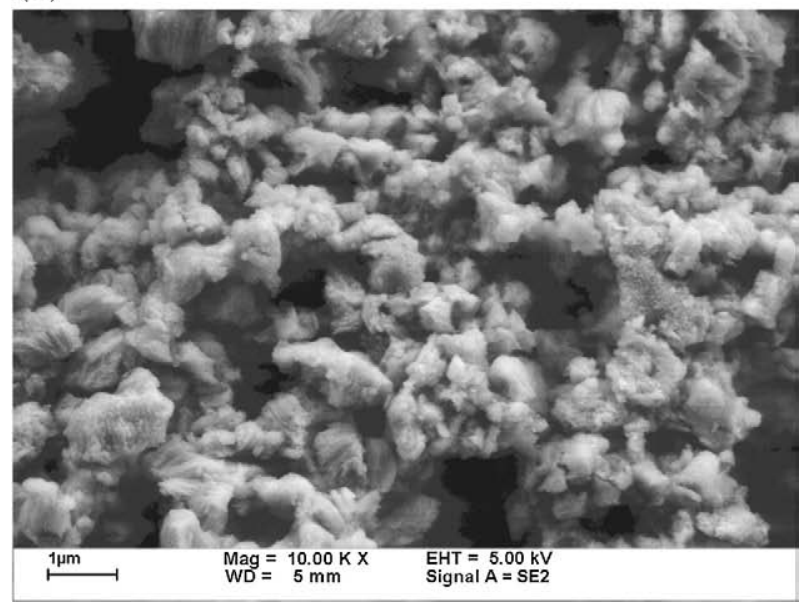

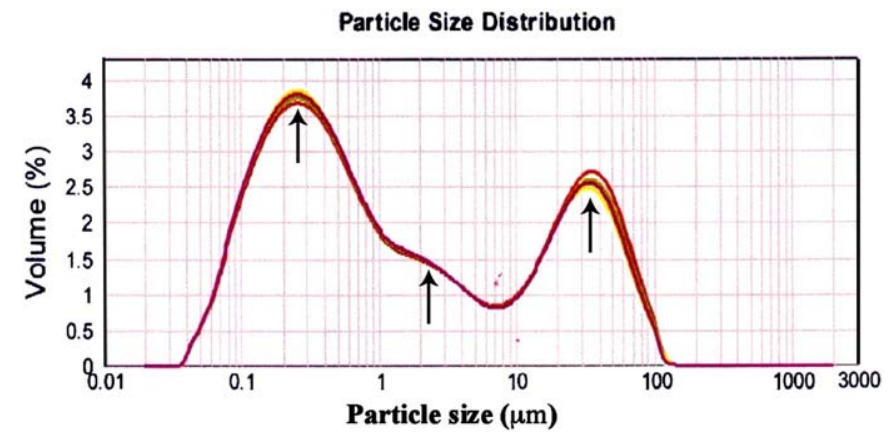

Fig. 2. Size distribution of DCPA and $\mathrm{Ca}(\mathrm{OH})_{2}$ powder mixture after attrition milling. The test was repeated for 3 times.

probe micro-analyzer (EPMA, Model JAX-8200, JOEL, Japan). The area mapping technique was employed to obtain the quantitative result.

\section{Results}

\subsection{Characterization of starting powders}

Fig. 1 shows the morphology of the starting DCPA and $\mathrm{Ca}(\mathrm{OH})_{2}$ powders. It is evident that the starting DCPA particles are larger than the $\mathrm{Ca}(\mathrm{OH})_{2}$ particles. The size distribution of the powder mixture after attrition milling is shown in Fig. 2. The size distribution measured for three times; the reproducibility is high. After attrition milling, the powder mixture shows a size distribution with three peaks, as indicated with arrows in Fig. 2. The sizes correspond to these three peaks from the left-hand side are $0.3 \mu \mathrm{m}, 2 \mu \mathrm{m}$ and $30 \mu \mathrm{m}$, respectively.

\subsection{Characterization of green compact}

Fig. 3 shows the fracture surface of a green powder compact prepared from the die-pressing of the powder mixture of DCPA and $\mathrm{Ca}(\mathrm{OH})_{2}$. The $\mathrm{DCPA}$ and $\mathrm{Ca}(\mathrm{OH})_{2}$ particles are packed closely to each other within the powder compact. The powder compact is uniform in terms of density distribution. Through the EDX analysis, some DCPA particles are identified. The size of the DCPA particles is around 1-2 $\mu \mathrm{m}$ and of the $\mathrm{Ca}(\mathrm{OH})_{2}$ particles is smaller than $0.5 \mu \mathrm{m}$. The three peaks in Fig. 2 can be related to the size of $\mathrm{Ca}(\mathrm{OH})_{2}$, DCPA and hard agglomerates, respectively.

\subsection{Phase analysis}

Fig. 4 shows the in-situ observation on the phase evolution of calcium phosphate cement in the first $24 \mathrm{~h}$. The XRD patterns for the starting DCPA (solid line) and $\mathrm{Ca}(\mathrm{OH})_{2}$ (dashed line) powders are also

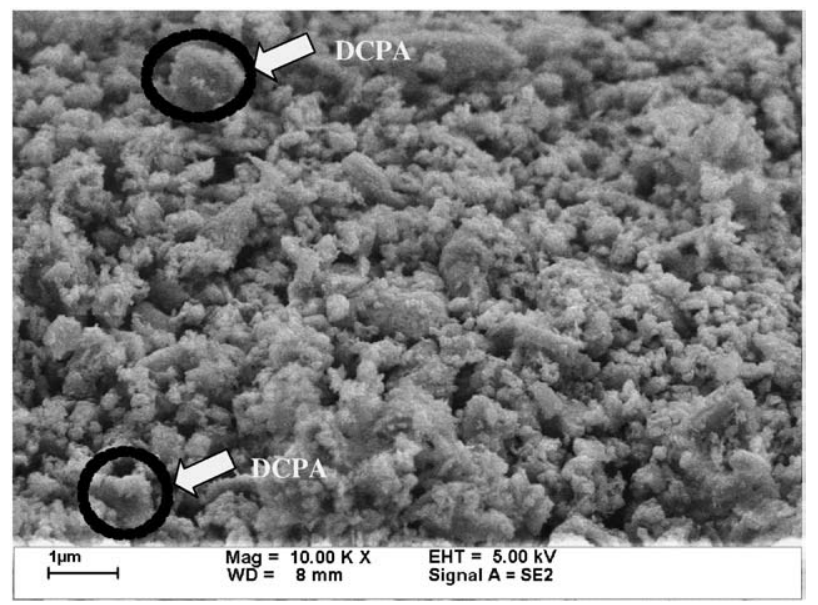

Fig. 3. Fracture surface of the powder compact before adding the cement liquid.

Fig. 1. Morphology of starting powders: (a) DCPA and (b) $\mathrm{Ca}(\mathrm{OH})_{2}$. 


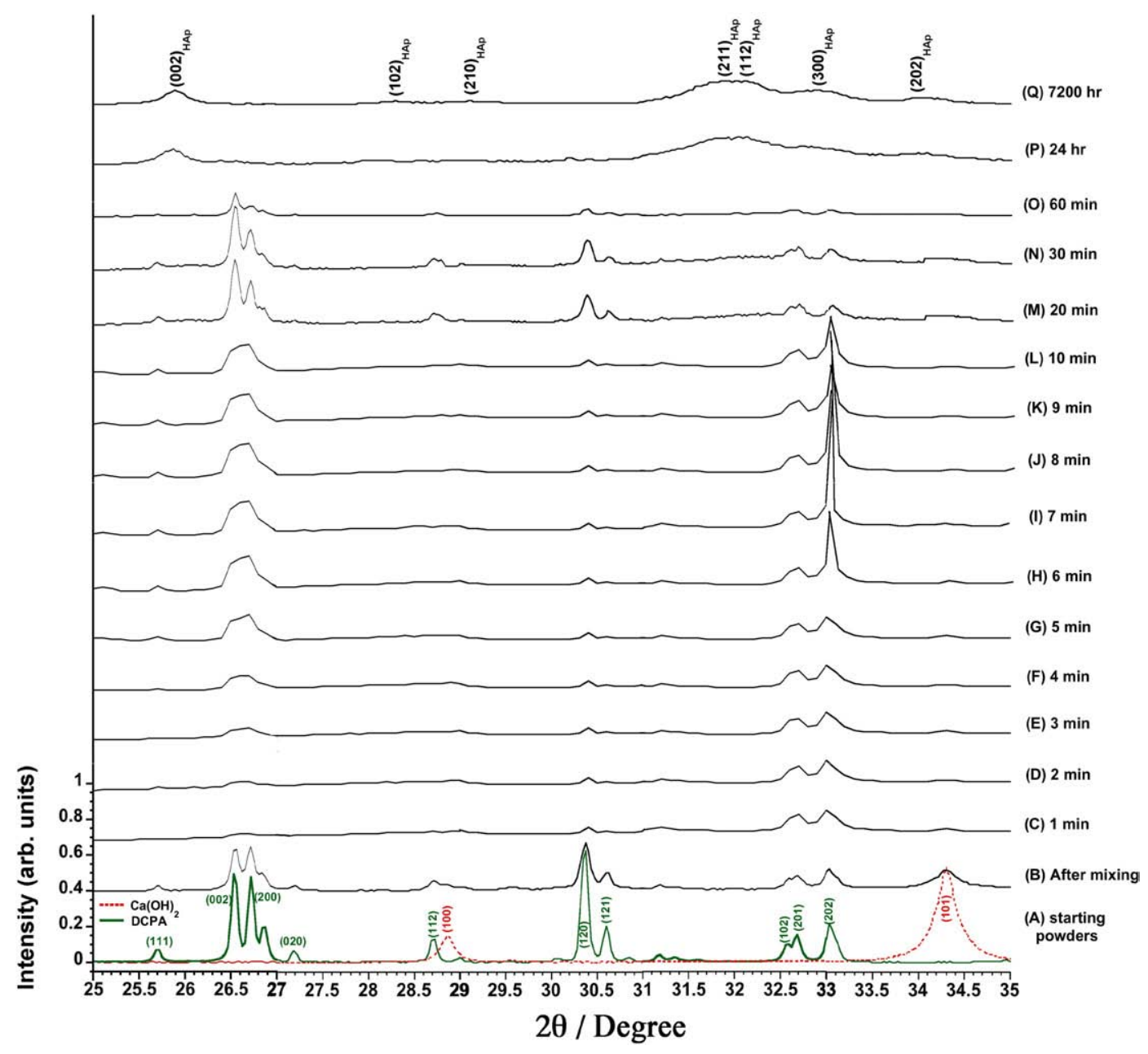

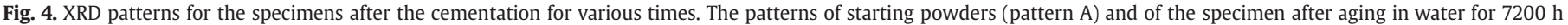
(pattern Q) are shown for comparison.

shown for comparison (pattern A). In the figure, pattern B shows the XRD pattern of the powder mixture after attrition milling for $6 \mathrm{~h}$. Though the width of the DCPA and $\mathrm{Ca}(\mathrm{OH})_{2}$ peaks remains the same after milling, the height of the XRD peaks reduces significantly. It indicates that the crystal structures of DCPA and $\mathrm{Ca}(\mathrm{OH})_{2}$ are seriously distorted after milling. After adding the cement liquid, $1.0 \mathrm{M} \mathrm{Na}_{2} \mathrm{HPO}_{4}$, into the powder compact composing of DCPA and $\mathrm{Ca}(\mathrm{OH})_{2}$, the intensity of $\mathrm{Ca}(\mathrm{OH})_{2}$ drops quickly within the first min (see pattern $\mathrm{C}$ in Fig. 4). Several DCPA peaks also decrease in intensity within the first min. However, the intensity of some DCPA peaks increases in the period of 5 to $20 \mathrm{~min}$. A very small amount of DCPA is still existed in the powder compact after $24 \mathrm{~h}$.

The extent of the transformation from calcium phosphate to hydroxyapatite can be estimated using the following Eq. [14]:

Transformation $(\%)=\left(\frac{\mathrm{HAp}_{t}-\mathrm{HAp}_{0}}{\mathrm{HAp}_{\infty}-\mathrm{HAp}_{0}}+\frac{1-\left(\frac{\mathrm{DCPA}_{t}}{\mathrm{DCPA}_{0}}\right)+1-\left(\frac{\mathrm{Ca}(\mathrm{OH})_{2, t}}{\mathrm{Ca}(\mathrm{OH})_{2,0}}\right)}{2}\right) \div 2 \times 100$

In the equation, $t$ is the reaction time. Since the intensity of the Ca $(\mathrm{OH})_{2}(101)$ peak, DCPA (202) peak and HAp (002) peak is high, and they are far away from the other peaks; these three peaks are chosen to estimate the amount of each phase. Since HAp is the only phase in the CPC after long-term aging in water [19], the intensity of the HAp (002) peak in pattern $\mathrm{Q}$ is used as the $\mathrm{HAp}_{\infty}$. The HAp peaks are first found after adding the cement liquid for $20 \mathrm{~min}$. Though there is no HAp peak found before $20 \mathrm{~min}$, a very small amount of HAp phase might be formed at this stage due to the size of newly formed HAp crystals is very small. By using the above equation, there is about $75 \%$ of the starting materials transformed to HAp after adding cement liquid for $24 \mathrm{~h}$.

The extent of transformation can also be estimated using the methodology employed by Ginebra et al. [15]. By adding the intensity of (002), (200), (020), (112), (120), (121), (102), (201), (202) peaks of DCPA, (100), (101) peaks of $\mathrm{Ca}(\mathrm{OH})_{2}$ and (002), (211), (112), (300), (202) peaks of HAp, and then normalizing with their original intensity (for DCPA and $\mathrm{Ca}(\mathrm{OH})_{2}$ ) or final intensity (for HAp), the transformation kinetics can be obtained. Fig. 5 shows the intensity ratio as a function of time. The amount of $\mathrm{Ca}(\mathrm{OH})_{2}$ decreases with increasing time. The intensity ratio of DCPA decreases first, and then it increases to a value higher than unity. This implies that some extra DCPA is formed.

\subsection{Microstructural analysis}

Fig. 6 shows the fracture surface of the powder compact after the reaction for $24 \mathrm{~h}$. Many large pores with size around $1 \mu \mathrm{m}$ are found. Many fine needle-like HAp particles with the dimensions of $40 \mathrm{~nm} \times 10 \mathrm{~nm}$ are found around the large pores (see Fig. 6b). Compared the microstructures of specimens before and after adding the cement liquid (see Figs. 3 and 6a), the large pores seem to originate from the starting DCPA particles. Fig. 7 shows the FT-IR patterns of the CPC specimens after adding the cement liquid for $1 \mathrm{~h}$ and $24 \mathrm{~h}$. The 


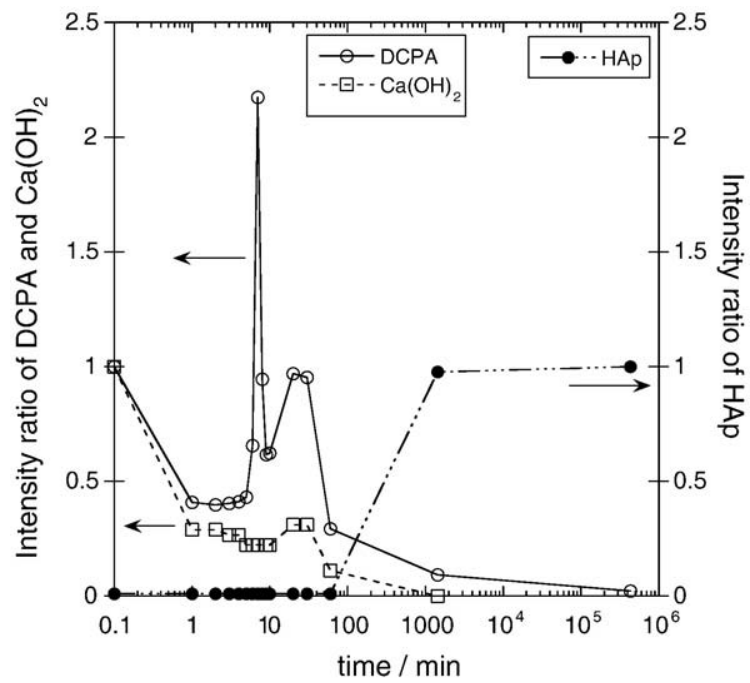

Fig. 5. Intensity ratio of $\mathrm{DCPA}, \mathrm{Ca}(\mathrm{OH})_{2}$ and $\mathrm{HAp}$ as a function of time.

FT-IR pattern of the specimen after aging in water for $7200 \mathrm{~h}$ is also shown for comparison. There is only HAp in the specimen after aging for $7200 \mathrm{~h}$ [19]. The functional legends for HAp are also found in the

(a)

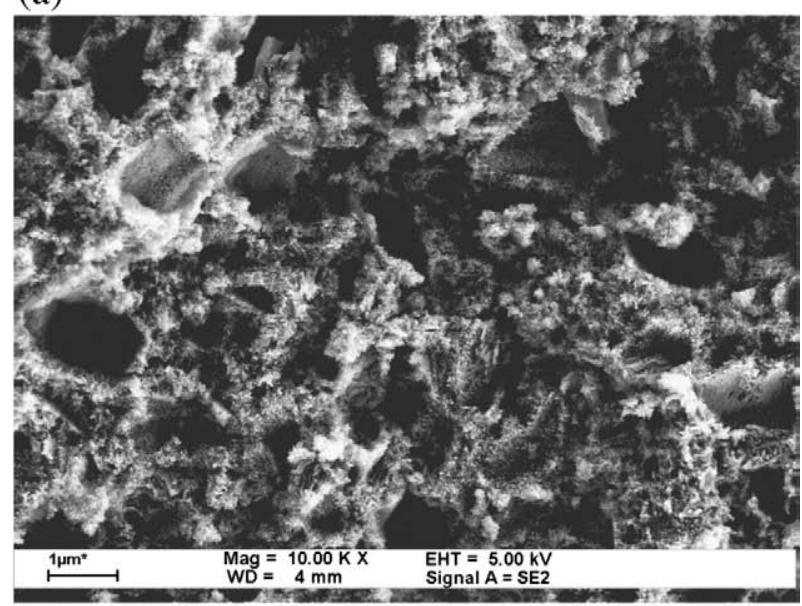

(b)

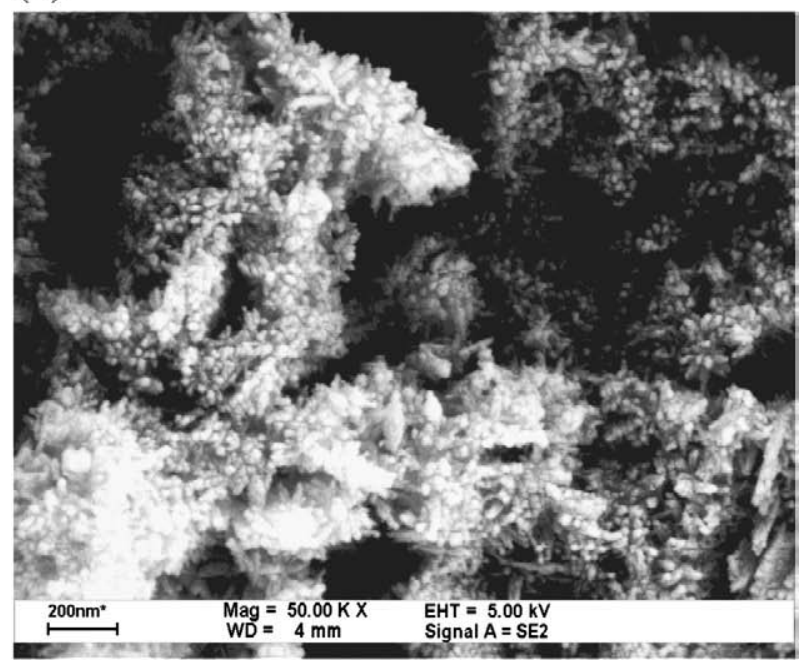

Fig. 6. Fracture surface (a) at lower magnification and (b) at higher magnification of a typical CPC specimen after adding the cement liquid for $24 \mathrm{~h}$.

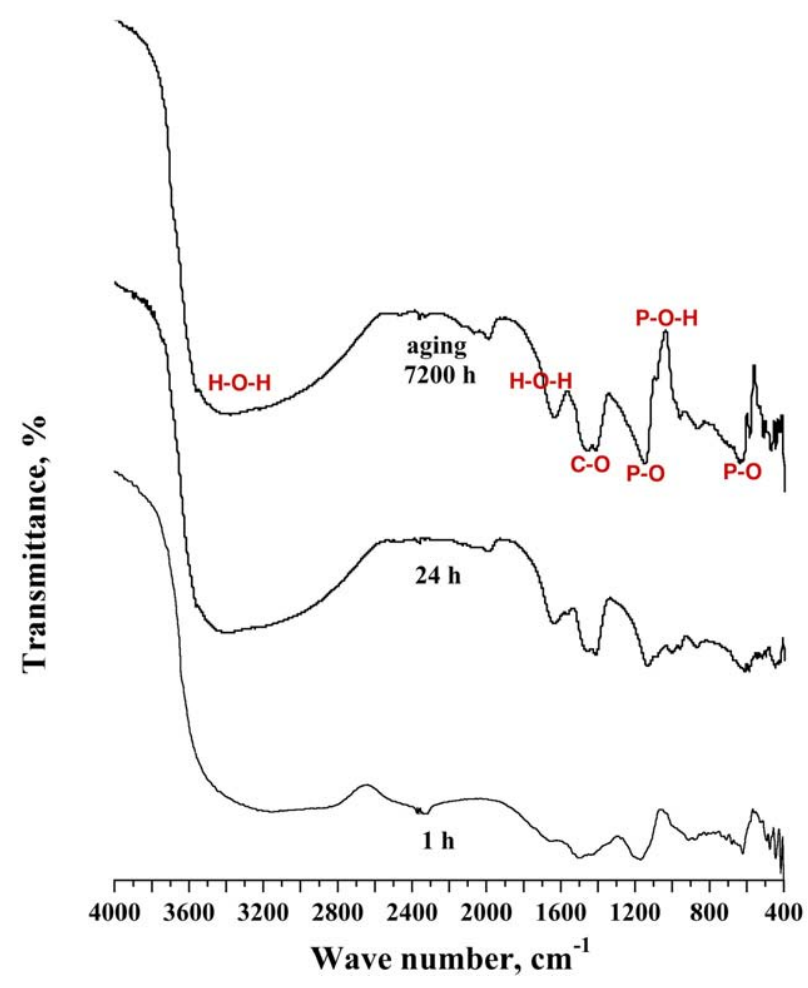

Fig. 7. FTIR patterns for the cement specimens after cementation for $1 \mathrm{~h}, 24 \mathrm{~h}$ and aging for $7200 \mathrm{~h}$.

specimen after adding the cement liquid for $1 \mathrm{~h}$, confirming that HAp is formed within $1 \mathrm{~h}$ of the cementation process.

\section{Discussion}

In the present study, an attrition milling technique is used to reduce the size of starting powders. A die-pressing technique is used to further increase the contacts between DCPA and $\mathrm{Ca}(\mathrm{OH})_{2}$ particles. Since the size of the DCPA particles is larger than that of the $\mathrm{Ca}(\mathrm{OH})_{2}$ particles, it is possible to identify the DCPA particles from the $\mathrm{Ca}(\mathrm{OH})_{2}$ particles in the starting powder compact (see Fig. 3). The porosity distribution in the powder compact before the reaction is relatively uniform. The large DCPA particles are always surrounded by many small $\mathrm{Ca}(\mathrm{OH})_{2}$ particles.

Owing to the intensity of the synchrotron X-ray beam is high, the reactions during setting can be monitored. Fig. 5 indicates that the intensity ratio of DCPA peaks may be higher than the starting intensity ratio in the period from 5 to 20 min, suggesting that some extra DCPA is formed, as demonstrated in the following reaction process [20],

$\mathrm{Ca}(\mathrm{OH})_{2(s)}+\mathrm{Na}_{2} \mathrm{HPO}_{4(s)}+2 \mathrm{H}_{2} \mathrm{O}_{(l)} \longrightarrow \mathrm{CaHPO}_{4(s)}+2 \mathrm{NaOH}_{(l)}+2 \mathrm{H}_{2} \mathrm{O}_{(l)}$

After 20 min, the intensity of all DCPA peaks then decreases. A very small amount of DCPA can still be found in the powder compact after $24 \mathrm{~h}$. Some HAp is found in the powder compact after adding the cement liquid for $20 \mathrm{~min}$. At this specific time, the amount of DCPA phase is decreased. It implies that the following reaction is taken place [20],

$10 \mathrm{CaHPO}_{4(s)}+2 \mathrm{H}_{2} \mathrm{O}_{(l)} \rightarrow \mathrm{Ca}_{10}\left(\mathrm{PO}_{4}\right)_{6}(\mathrm{OH})_{2(s)}+4 \mathrm{H}_{3} \mathrm{PO}_{4(l)}+\mathrm{H}_{2} \mathrm{O}_{(l)}$

The formation of HAp is also confirmed by the FTIR analysis. Since there is no tricalcium phosphate (TCP) found in the XRD patterns, suggesting that the apatite phase is a HAp phase. Furthermore, the EPMA analysis shows that the $\mathrm{Ca} / \mathrm{P}$ ratio of the HAp particles is 1.66 , 
which is close to that of the stoichiometric HAp. During the cementation process, the intensity of the DCPA peaks decreases first, then increases, and then decreases again with increasing reaction time. This suggests that the dissolution and precipitation processes are taken place. The planes with high chemical reactivity are dissolved first, and then precipitate onto the planes with low chemical activity. The formation of HAp seems to be resulted from the interaction of the "old" DCPA phase with the "new" DCPA phase.

Attrition milling is a powerful technique to reduce the size of brittle ceramic particles. By using the attrition milling for $6 \mathrm{~h}$, the size of $\mathrm{Ca}(\mathrm{OH})_{2}$ and DCPA particles is significantly reduced. The reduction in the particle size enhances the reaction rate. Therefore, the reaction is started as soon as the cement liquid is added into the powder mixture of DCPA and $\mathrm{Ca}(\mathrm{OH})_{2}$. Though the reaction is fast, the DCPA remains after $24 \mathrm{~h}$. Since the calcium phosphate cement is usually inserted into the bone stock within a relatively short time, the DCPA is likely present after the insertion into body. The dissolution rate of DCPA (log Ksp=-6.90) in body liquid is faster than that of HAp (log $\mathrm{Ksp}=-58.4$ ) [21]. Though the hydroxyapatite prepared from CPC is stable in water over a period of 300 days [19], the CPC may lose its integrity if the amount of DCPA is large.

\section{Conclusions}

Through the dissolution and precipitation processes, an amount around $75 \%$ calcium phosphate cement is transformed into hydroxyapatite within $24 \mathrm{~h}$. In-situ phase analyses indicate that $\mathrm{Ca}(\mathrm{OH})_{2}$ is disappeared first, and then the extra DCPA phase is formed within a short period of time to assist the formation of HAp phase. Large pores are left behind at the original locations for the DCPA particle. A tiny amount of DCPA remains in the powder compact $24 \mathrm{~h}$ after the start of the setting reaction.

\section{Acknowledgments}

Valuable comments given by Prof. Dean-Mo Liu, Dept. of Mater. Sci. \& Eng., National Chiao-Tung University, and Prof. Jay Shieh, Dept. of Mater. Sci. \& Eng., National Taiwan University, are highly appreciated.

\section{References}

[1] W.E. Brown, L.C. Chow, in: P.W. Brown (Ed.), in Cements research progress, Am. Ceram. Soc., 1986, p. 352, Westerville, OH.

[2] F.C.M. Driessens, R.K. Verbeeck, Biominerals, CRC Press, New York, 1990.

[3] A.J. Ambard, L. Mueninghoff, J. of Prosthodontics 15 (2006) 321.

[4] M. Watanabe, M. Tanaka, M. Sakurai, M. Maeda, J. Euro. Ceram. Soc 26 (2006) 549.

[5] Z. Amjad, Calcium Phosphates in Biological and Industrial Systems, Kluwer Academic Publisher, 1998.

[6] M.P. Ginebra, E. Fernandez, E.A.P. De Maeyerl, R.M.H. Verbeeck, M.G. Boltong, J. Ginebra, F.C.M. Driessens, J.A. Planell, J. Dent. Res 76 (1997) 905.

[7] Y. Miyamoto, K. Ishikawa, H. Fukao, M. Sawada, M. Nagayama, M. Kon, K. Asaoka, Biomater 16 (1995) 855

[8] K. Ishikawa, S. Takagi, L.C. Chow, Y. Ishikawa, J. Mater. Sco. Mater. Med 6 (1995) 528.

[9] H. Monma, M. Goto, T. Konmura, Gypsum and Lime 188 (1984) 11.

[10] B.R. Constanz, B. Barr, K. McVicker, United Patent 5,053,212 (1991)

[11] S. Takagi, L.C. Chow, J. Mater. Sci. Mater. In Med 12 (2001) 135.

[12] Q. Yang, T. Troczynski, D.-M. Liu, Biomater 23 (2002) 2751.

[13] U. Gbureck, O. Grolms, J.E. Barralet, L.M. Grover, R. Thull, Biomateri 24 (2003) 4123.

[14] E.I. Dorozhkina, S.V. Dorozhkin, Chem. Mater 14 (2002) 4267.

[15] M.P. Ginebra, F.C.M. Driessens, J.A. Planell, Biomater 25 (2004) 3453.

[16] F.C.M. Driessens, M.G. Boltong, E.A.P.D. Maeyer, R.M.H. Verbeeck, R. Wenz, J. Mater. Sci.: Mater. in Med 11 (2000) 453.

[17] S. Serraj, P. Boudeville, A. Terol, J. Mater. Sci.: Mater. in Med 12 (2001) 45

[18] L. Sun, H.H.K. Xu, S. Takagi, L.C. Chow, J. Biomater. Appl 21 (2007) 299

[19] H.C. Hsu, C.Y. Chiu, W.H. Tuan, H.Y. Lee, Mater. Sci. \& Eng. C 28 (2008) 429.

[20] L.L. Hench, J. Wilson, An introduction to bioceramics, Word Scientific, Singapore, 1993.

[21] L.C. Chow, E.D. Eanes, in: S. Karger, A.G. Basel (Eds.), Octacalcium phosphate, 2001. 